\title{
CONFLITO, PROTESTO E PROCEDIMENTO NA TEORIA DE SISTEMAS DE NIKLAS LUHMANN
}

\author{
João Paulo Bachur \\ Advogado. Doutor em Ciência Política pela USP. Professor do Instituto Brasiliense de \\ Direito Público (IDP) em Brasília/DF e do Insper em São Paulo/SP.
}

\begin{abstract}
Resumo: A sociedade contemporânea, descrita pela teoria de sistemas sociais de Niklas Luhmann como sociedade funcionalmente diferenciada, estabiliza-se pela contradição. Contrariando uma intuição clássica da teoria social, a contradição se torna um fator de preservação das estruturas sociais e não seria exagero reconhecer que a sociedade se revela tão mais integrada quanto maior seja sua capacidade de operar a contradição. 0 objetivo deste artigo é desenvolver este argumento tendo como fio condutor a articulação conceitual entre conflito, procedimento e os chamados movimentos de protesto - os tradicionais mecanismos para a reivindicação de direitos individuais e coletivos - no contexto da teoria de sistemas sociais de Luhmann.
\end{abstract}

Palavras-chave: Niklas Luhmann. Teoria de sistemas sociais. Conflito. Movimentos de protesto.

Sumário: 1 Introdução: conflito, contradição e dinâmica social - 2 Conflito como sistema social 3 Procedimento - $\mathbf{4}$ Protesto - $\mathbf{5}$ Conclusão - Referências

\section{Introdução: conflito, contradição e dinâmica social}

O conflito é uma das categorias conceituais que permeia a moderna teoria social de maneira razoavelmente ininterrupta: pelo menos desde os Discorsi de Machiavelli até a dialética do senhor e do escravo de Hegel, passando com destaque pela "guerra de todos contra todos" de Hobbes, o conflito passa a ser o grande responsável pela dinâmica social, consolidando-se assim uma profunda ruptura com a noção aristotélica do homem como zoon politikon - homem que tende por natureza à associação e que, justamente por isso, só se realiza plenamente na comunidade política (HONNETH, 1992). Rompendo com essa garantia derivada da natureza humana, o conflito passara a expressar a contingência da associação política - cuja superação, pelo menos até o contratualismo do século XVIII, exigia uma solução racional.

Da economia política clássica, por sua vez, derivava não a associação política, mas a formação econômica da sociedade de uma tendência inexorável à troca de 
mercadorias. Com isso, ela assumiu e naturalizou o conflito como concorrência de interesses privados, movida pela busca do self-love de Adam Smith, para citarmos apenas a formulação canônica. Mesmo quando a filosofia moral de um Bernard de Mandeville, por exemplo, classificava essa busca tão somente como um vício moral que, nessa medida, estaria restrito ao âmbito privado da conduta individual, os resultados daí decorrentes poderiam ser tidos como benefícios públicos.

Não é à toa que, em Hegel, a sociedade civil é caracterizada pelo antagonismo de um sistema de carências no qual a eticidade fica "perdida nos seus extremos", pois "A sociedade civil é a diferença que intervém entre a família e o Estado"; abrindo assim uma cisão que somente poderia ser reconciliada por uma esfera de moralidade objetiva superior - o Estado como realização ética, i.e., como eticidade ou moralidade objetiva, como Sittlichkeit, portanto (HEGEL, 1995, §182, adendo, p. 339; §258, adendo, p. 403).

Essa configuração do Estado como a instância (moral, no caso de Hegel) capaz de superar a cisão da sociedade civil é incorporada por Marx no quadro de uma teoria da revolução, pois somente assim seria possivel superar sua organização burguesa - e, dessa forma, o aparato estatal deixaria de ser o apêndice burocrático que representa os interesses particulares de uma classe social específica como se fossem interesses universais (KOUVELAKIS, 2003, p. 251). É certo que, n'O dezoito brumário, contudo, Marx argumenta que a máquina do Estado parece ter se tornado completamente autônoma ante a sociedade civil, sugerindo uma diferenciação efetiva entre sociedade civil e Estado, i.e., entre economia e política, que tornaria a própria possibilidade da alternativa revolucionária teoricamente questionável (MARX, 1852, p. 197). Em Marx, o conflito passa a ser constitutivo da formação social: não por outra razão, a luta de classes é o dínamo responsável tanto pelo desenvolvimento das forças produtivas quanto pelas contradições entre essas forças produtivas e as relações de produção, uma contradição que converte a sociedade em um antagonismo bipolar estruturante que somente poderia ser resolvido pela revolução (MARX; ENGELS, 1848, p. $462-463)$.

No entanto, seria possível identificar um momento em que o próprio Marx, como que ponderando a viabilidade da alternativa revolucionária, aventara também a possibilidade de que o conflito entre capital e trabalho, uma vez disciplinado democraticamente, deixasse de ser uma força intrinsecamente revolucionária:

Rompeu-se o acento revolucionário das reivindicações sociais do proletariado, dando-se a elas uma virada democrática; extraiu-se das pretensões democráticas da pequena burguesia apenas sua forma política, dando-Ihe ares de socialista. Assim surgiu a social-democracia. [...] 0 caráter singular da social-democracia resume-se assim 
a isto: instituições democráticas e republicanas são exigidas como meio não para a superação de dois extremos, capital e trabalho assalariado, mas para enfraquecer o antagonismo entre eles e transformá-lo em harmonia. (MARX, 1852, p. 141) (Grifos no original)

Com efeito, se o antagonismo entre burguesia e proletariado marca historicamente a cristalização do capitalismo, o capitalismo "vitorioso", no sentido em que Weber (1904/1905, p. 154) emprega essa expressão, altera ele próprio o significado desse antagonismo, como ficaria claro na história política das democracias ocidentais industrializadas. É claro que, com o advento da social-democracia - para além da crítica de Marx há pouco mencionada, i.e., compreendendo-se aqui a generalização do modelo democrático de welfare state no ocidente industrializado na segunda metade do século XX - a noção de que o conflito social passara a articular institucionalmente transformação e preservação social se incorporou ao cotidiano da teoria política. Daí em diante a vasta literatura que se acumula sobre o tema ainda ressoa esse entendimento (cf., e.g., DAHRENDORF, 1957; HIRSCHMAN, 1994; OFFE, 1986).

E, com efeito, essa vinculação originária entre conflito e transformação social ainda pode ser identificada na literatura sobre os novos movimentos sociais, independentemente da perspectiva marxiana que articulava teoria de classes e teoria da revolução (cf., e.g., HABERMAS, 1981, v. 2, p. 576; GOHN, 1997; DOMINGUES; BRINGEL, 2012). A reivindicação de direitos se corporifica hoje nos assim chamados "novos movimentos sociais" (EDER, 1985; COHEN, 1985; TILLY, 1985; TOURAINE, 1985).

Mas se é verdade que a literatura sobre os novos movimentos sociais tende em geral a relacioná-los com o histórico das teorias de classe, de forma a ressaltar as diferenças entre esses dois tipos de ação política coletiva, a dinâmica entre esses movimentos e o governo geralmente passa despercebida. De fato, os movimentos sociais nas democracias industrializadas geralmente têm como objeto uma reação crítica à atividade estatal (HALFMANN, 1984, p. 297): seja para exigir que o Estado ou o governo se abstenham de tomar alguma decisão (e.g., evitar a construção de uma usina nuclear); seja para exigir do Estado ou do governo alguma decisão (e.g., maior regulamentação dos mercados financeiros, maior responsabilização das agências internacionais de análise de risco financeiro etc.). O Estado, por sua vez, reage à crítica recebida pelos movimentos sociais por meios de seus mecanismos decisórios.

O objeto deste artigo é identificar a dinâmica entre os movimentos sociais e os procedimentos decisórios institucionais no enquadramento da teoria de sistemas sociais de Niklas Luhmann. Em uma formulação um pouco mais abstrata, trata-se de analisar como o conflito articula a diferença mudança/ 
conservação social, demonstrando os fundamentos pelos quais essa articulação ocorre de maneira paradoxal. A sociedade contemporânea, descrita por Luhmann (1997) como sociedade funcionalmente diferenciada, estabiliza-se na verdade pela contradição: ela reage às suas próprias contradições gerando novas contradições que se compensam reciprocamente. Esse caráter intrinsecamente contraditório da sociedade funcionalmente diferenciada não é suficientemente destacado por Luhmann (nem pelo marxismo convencional, que sempre apostara dogmaticamente na contradição social como mecanismo de transformação). O objetivo deste artigo é demonstrar este aspecto, explorando a contradição que se estabelece concretamente entre os movimentos de protesto e os procedimentos políticos oficiais para a tomada de decisões coletivamente vinculantes.

Contrariando uma intuição clássica da teoria social segundo a qual o conflito e a contradição são responsáveis pela dinâmica de alterações estruturais na sociedade (seja pela via revolucionária do jovem Marx, seja pela via do conflito institucionalizado democraticamente na linha de Dahrendorf e Offe, ou ainda pela via do agir comunicativo de Habermas ou da luta por reconhecimento de Honneth) as contradições da sociedade funcionalmente diferenciada se tornam ao contrário um fator de preservação das estruturas sociais. E não seria exagero reconhecer que a sociedade se revela tão mais integrada quanto maior seja sua capacidade de lidar com a contradição.

Este artigo desenvolve esse argumento tendo como fio condutor a articulação conceitual entre conflito, procedimento e o que Luhmann designa como movimentos de protesto (Protestbewegungen). Para tanto, o artigo situa brevemente o conflito no contexto da diferenciação funcional da sociedade (seção 2) e analisa as duas formas pelas quais a sociedade reage às suas próprias contradições: procedimentos decisórios (seção 3) e movimentos de protesto (seção 4). Ao final, veremos que: (i) protesto e procedimento, costumeiramente vistos como categorias antagônicas, na verdade se complementam como estruturas funcionais de um sistema político funcionalmente diferenciado; (ii) o que permite identificar na dinâmica estabelecida entre procedimentos decisórios e movimentos de protesto uma lógica paradoxal - ou "dialética", para utilizarmos a terminologia tradicional da teoria crítica da sociedade: a contestação da sociedade é convertida em sua afirmação. Como se verá, a releitura aqui proposta da teoria de sistemas permite uma visada crítica da dinâmica política da sociedade contemporânea, inclusive por meio da verificação de efeitos paradoxais e contraditórios das modernas formas de atuação política coletiva. 


\section{Conflito como sistema social}

Para este trabalho interessa menos uma visão de conjunto da vasta produção de Luhmann do que uma abordagem localizada capaz de proporcionar uma apropriação da teoria de sistemas sociais para lidar com temas centrais da sociologia jurídica e da teoria política contemporâneas.

Sistemas sociais são sistemas autorreferenciais: constituem-se pela diferença entre cada sistema e seu ambiente, de sorte que a diferenciação funcional dos sistemas ocorre com a replicação da diferença "sistema/ambiente" internamente a cada sistema (LUHMANN, 1984, p. 22-25; 1997, p. 609). A formulação é a aplicação do conceito de forma de George Spencer Brown: uma forma é sempre uma marcação de dois lados, de sorte que um observador está adstrito a apenas um desses lados, conquanto certo da existência do outro lado, não observável, que remanesce como um espaço não marcado (unmarked space). Com isso, a forma é sempre um fechamento determinado, a indicação de um âmbito cerrado. Essa forma pode ser replicada internamente como re-entrada (re-entry) da forma dentro da forma, ou seja, como uma distinção (forma/ unmarked space) replicada no lado indicado pelo observador, i.e., em seu lado interno (cf. SPENCER-BROWN, 1973, p. 69-76).

A formulação pode parecer excessivamente abstrata nesses termos, mas a contextualização, por exemplo, no caso do sistema político, pode ajudar. A política, compreendida como sistema autopoiético, é a unidade da diferença sistema/ ambiente, portanto, é a unidade da diferença política/sociedade. Essa diferença é paradoxal porque diz, a um só tempo, que a política é e não é sociedade, por assim dizer: ao mesmo tempo em que ela não existe fora nem está acima da sociedade, nem detém qualquer privilégio funcional sobre os demais sistemas autopoiéticos da sociedade (economia, direito, arte etc.); ela desempenha uma função que atende à sociedade considerada como um todo e, nesse sentido, ela pode ser considerada uma atualização funcional da sociedade. A política se diferencia da sociedade ao erguer uma barreira de indiferença com relação a seu ambiente (a sociedade considerada como um todo e os outros subsistemas funcionais) que, neste ato de distinção, ela própria cria. Essa barreira é construída quando a diferença política/sociedade é replicada internamente no lado interno da forma (no lado da política).

Assim, para que a política consiga se definir como sistema autopoiético (i.e., para que ela se diferencie do restante da sociedade), ela emprega a codificação binária governo/oposição. Admitindo que a função da política seja definida pela "preservação da capacidade de tomar decisões coletivamente vinculantes" (LUHMANN, 2000, p. 84), e isto não apenas em termos eleitorais, mas também 
em termos administrativos e legislativos, tudo que acontece na política acontece como exercício de poder pelo governo ou pela oposição (isso não quer dizer que governo e oposição tenham que estar presentes na tomada de decisão: decisões de agências reguladoras ou de órgãos do Poder Executivo são tomadas apenas pelo governo - mas as repercussões das decisões, seu "erro" ou "acerto" são registrados pela sociedade como ponto do governo ou da oposição).

Isso não quer dizer que a opinião pública e a sociedade civil organizada, para ficarmos com os exemplos mais elementares, não tenham relevância política: toda a sociedade faz aportes temáticos para a política, isto é, apresenta temas que desencadeiam discussões políticas que podem conduzir a uma decisão coletivamente vinculante. Mas essa decisão, quando tomada, somente pode acontecer pela atuação conjunta de governo e oposição. Ou seja, a comunicação política está estruturada pela disputa entre governo e oposição (eleições, nomeações para cargos administrativos, lançamento de uma candidatura ou de um programa de governo, obstrução a votações parlamentares, instalação de comissões parlamentares especiais, apresentação de emendas a projetos de lei, ajuizamento de ações no poder judiciário etc.). Não importa de onde tenha partido a irritação que desencadeou operações políticas; as decisões políticas propriamente ditas somente podem ser compreendidas como ação do governo ou da oposição, ou ainda da disputa entre ambos. A figura seguinte pretende oferecer uma ilustração gráfica dessa formulação conceitual:

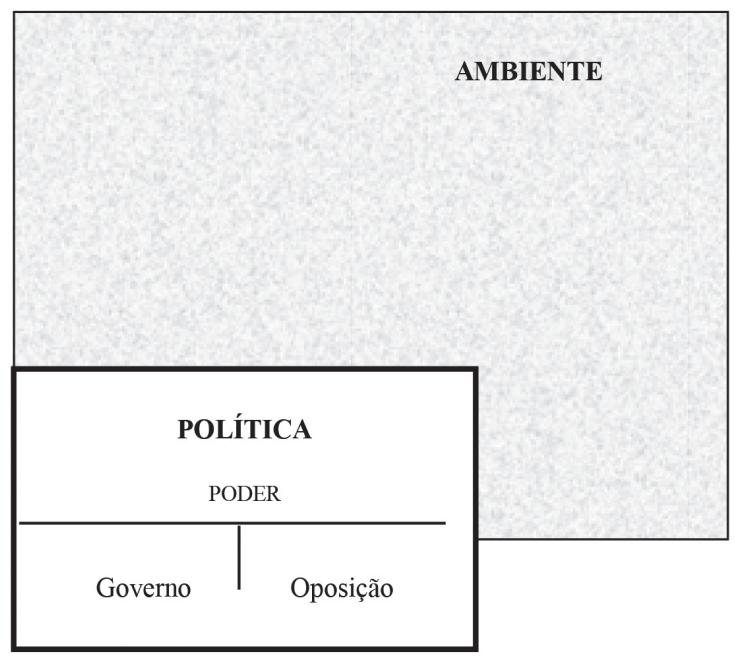


O importante nessa definição de sistema é o fechamento ou a clausura operacional (operative Geschlossenheit). Para Luhmann, a sociedade não é composta pelos indivíduos concretos e por seus interesses, suas consciências e suas ações (entendendo-se ação como atuação instrumental decorrente da consciência): a única operação genuinamente social é a comunicação - por isso a teoria da sociedade de Luhmann se define como teoria de sistemas: apenas nos sistemas (mas nunca entre sistemas) é possível comunicação.

Os sistemas são diferenciações comunicativas estruturadas socialmente, incumbidas de desempenhar uma função em caráter exclusivo, e essa função é sempre comunicação (LUHMANN, 1984, p. 191-193; e, especificamente, 2005, p. 109-120). O direito não se comunica com a economia ou com a política pelo contrário, trata-se de assegurar que a comunicação jurídica aconteça apenas internamente ao sistema jurídico e que a comunicação econômica, apenas internamente ao sistema econômico etc.

Donde o fechamento operacional: ainda no exemplo da política, a comunicação política não pode ser desempenhada pela comunicação científica, que não pode ser desempenhada pela comunicação erótica nem pela comunicação econômica; só a política pode organizar a disputa entre governo e oposição e, nesse passo, reproduzir a si mesmo. Com isso, tem-se a política como um sistema social autorreferencial, autopoiético e operativamente fechado, embora fique mantida uma abertura cognitiva para o ambiente: a política recebe irritação de todos os demais sistemas sociais, mas codifica a informação como tema passível de ser tratado politicamente, i.e., passível de uma decisão coletiva.

Os sistemas são constituídos socialmente conforme um princípio evolutivo de diferenciação funcional. Evolutivamente, existem quatro padrões de diferenciação da sociedade, quais sejam: (i) diferenciação segmentária, típica das sociedades arcaicas fundadas no parentesco e na vizinhança, pautada pela igualdade na formação dos sistemas; (ii) diferenciação centro/periferia, um modo transitório de diferenciação baseado na distinção cidade/campo e que força uma sobrediferenciação por estratos no centro e segmentária na periferia; (iii) diferenciação por estratificação, fundada em um princípio de hierarquia de níveis sociais, tipicamente feudal; e, finalmente, (iv) a diferenciação funcional, estabelecida conforme o desempenho de funções relevantes para a sociedade considerada como um todo.

A diferenciação funcional significa o desempenho de determinada função social que serve à sociedade considerada como um todo por um único sistema (LUHMANN, 1997, p. 747). Por exemplo: a disciplina das relações de mercado é monopólio da economia, a tomada de decisões coletivamente vinculantes é um monopólio da política; internamente à política, a aprovação de leis e de emendas 
constitucionais é monopólio de uma instituição parlamentar etc. Por isso, a diferenciação funcional impede que um sistema controle ou exerça qualquer influência determinante no desempenho das funções de outros sistemas: a renúncia à possibilidade de uma coordenação centralizada das funções intersistêmicas é imediatamente correlata ao primado da diferenciação funcional. A política até considera os efeitos de suas leis sobre a formação de preços ou sobre a vida privada das famílias, mas as decisões coletivamente vinculantes são tomadas com base em relações de poder. 0 primado da diferenciação funcional implica ao mesmo tempo o monopólio de funções por sistemas e subsistemas específicos e a impossibilidade de uma coordenação intersistêmica centralizada - uma centralização que, remotamente, estava a cargo da religião (cf. LUHMANN, 1977, p. 50; 1997, p. 709; BACHUR, 2011).

O monopólio funcional implica a irradiação de efeitos do desempenho de uma função por um sistema para outros sistemas que é percebida, nesta medida, como irritação, como distúrbio. Isso significa que determinado fenômeno - uma crise inflacionária, por exemplo - terá tratamentos distintos pela economia, pela política, pelo direito, pelas famílias etc., e que seus efeitos até podem vir a ser observados como uma unidade por um observador, mas não poderão ser socialmente coordenados por uma instância única que detenha uma observação privilegiada (LUHMANN, 1997, p. 753).

Sistemas não são substâncias essenciais: o sistema político não se define por uma essência política (imaginemos como exemplo a fórmula da "autodeterminação coletiva" ou do "bem comum", assim como a economia não se define pela "satisfação das necessidades"). Aqui é preciso atentar para o fato de que os sistemas são formas, no sentido que Luhmann apropria este conceito de George Spencer-Brown (1973): a unidade de uma diferença expressa em uma forma de dois lados. Inexistindo uma substância inata a cada sistema, a teoria de sistemas sociais de Luhmann abre espaço para a observação de sistemas ortogonais à reprodução autopoiética das principais funções da sociedade: sistemas ad hoc internos aos principais sistemas sociais que desempenham funções específicas para eles - e não para a sociedade como um todo. Conflito, procedimento e movimentos de protesto são sistemas ortogonais desse tipo.

São circuitos comunicativos estruturados por uma diferença sistema/ ambiente específica, interna aos sistemas autopoiéticos individuais. Portanto, conflito, procedimento e movimentos de protesto são subsistemas que podem ser construídos para lidar com as mais variadas situações originadas nos demais sistemas autopoiéticos da sociedade. E, via de regra (apesar de não ser um ponto suficientemente destacado por Luhmann), essas situações estão relacionadas à reivindicação de direitos (individuais ou coletivos). 
O conflito, na teoria de sistemas, está relacionado às contradições e incongruências verificadas em função da operação concomitante de sistemas autopoiéticos que não podem ser submetidos a uma coordenação central: ao reproduzirem suas fronteiras específicas, os sistemas sociais (economia, direito, política etc.) produzem reciprocamente ruído e irritação: uma decisão política que aumente a carga tributária exige ajuste e planejamento por parte das empresas; novas descobertas científicas alteram disputas de mercado; decisões judiciais podem pôr em dúvida leis e outras decisões políticas e assim por diante.

Naturalmente, a operação "normal" dos sistemas sociais produz externalidades (positivas e negativas), para usarmos uma metáfora da teoria econômica, que afetam a comunicação nos demais sistemas da sociedade. Sistemas autopoiéticos contam com um filtro de indiferença a fim de que nem toda irritação coloque imediatamente em risco a reprodução autopoiética da comunicação, mas há casos em que a reprodução da diferença sistema/ambiente pode estar ameaçada. Nesses casos, opera o sistema social conflito.

O conflito é, na verdade, a construção de um sistema social particular para apreender e reduzir a complexidade gerada por expectativas comunicativas incongruentes, com as quais ele tem de lidar. Quando uma comunicação é contraditada, põe-se a negação comunicativa entre parênteses, como forma de preservar a autopoiese do sistema principal. Na teoria de sistemas sociais, os conflitos não ocorrem entre pessoas, pois a unidade analítica da teoria não está nas consciências ou na racionalidade individual, mas na comunicação - as pessoas são construções dos sistemas para a imputação de ações. Pensemos, por exemplo, no caso dos burgueses e proletários: o que Marx descrevera como antagonismo estrutural e fundante da sociedade moderna é visto por Luhmann como construção do sistema econômico funcionalmente diferenciado, constelações de expectativas que funcionam como suporte material para a comunicação econômica. Comparado ao cânone sociológico, o conflito em Luhmann tem mais da Zwischenbetrachtung de Weber do que do Manifesto de Marx e Engels, justamente porque a incongruência dos conflitos sociais - que, multiplicados pela diferenciação funcional, já não podem ser reconduzidos a uma instância última socialmente privilegiada - decorre do jogo dos múltiplos sistemas sociais em suas respectivas “legalidades próprias” (Eigengesetzlichkeiten):

[Os] tipos de conflitos entre "esferas vitais", construídos intelectualmente, não expressam nada além disto: nesse contexto, tais conflitos são intrinsecamente possíveis e "adequados" - mas de maneira alguma que: haveria um ponto de vista a partir do qual eles pudessem ser considerados “superados" [aufgehoben]. (WEBER, 1920, p. 537) (Grifos no original) 
Nesse ponto específico há uma convergência imediata entre Weber e Luhmann: a impossibilidade de que um âmbito social detenha a priori uma prerrogativa de anterioridade ou de determinação em relação a todos os outros (ambos têm em mente a dedução da superestrutura ideológica a partir da base econômica). Para Luhmann, o conflito se relaciona muito mais às disfunções reciprocamente geradas pelas lógicas autonomizadas dos sistemas sociais do que ao antagonismo de interesses. Não obstante essa convergência, a tradução luhmanniana do conflito tem como conceito central a categoria da comunicação.

$\mathrm{Na}$ teoria de sistemas sociais, tem-se conflito sempre que uma comunicação é contraditada ou quando uma contradição é comunicada. Só há conflito quando se comunica uma expectativa e a não aceitação da comunicação acerca dessa expectativa. Conflito, portanto, é relacionado a um processo comunicativo concreto e empiricamente apreensivel: trata-se de "um "não" comunicado, que responde a uma comunicação anterior" (LUHMANN, 1984, p. 530). Evidentemente, não é possível assimilar este "não" a um ato de fala, no sentido da filosofia analítica da linguagem: trata-se de uma negativa estruturada socialmente para contraditar expectativas. Pensemos em alguns exemplos para concretizar essas reflexões: lembremos, por exemplo, no movimento pelo "passe livre" dos estudantes em junho de 2013, ou na greve dos caminhoneiros de maio de 2018. É certo que, no primeiro caso, o conflito evoluiu e abarcou muitas outras pautas além da questão da mobilidade urbana dos estudantes (NOBRE, 2013). No entanto, especificamente quanto à reivindicação pelo passe livre estudantil, o conflito estava estruturado da seguinte maneira, em termos luhmannianos: "Passe livre estudantil: sim ou não?". Os estudantes encarnavam o "sim", as autoridades governamentais o "não". Da mesma maneira, a greve dos caminhoneiros expressou a reivindicação por melhores condições de trabalho da categoria dos caminhoneiros estruturada em um conflito que, em termos de teoria de sistemas, poderia ser traduzido da seguinte maneira: "Subsídios governamentais aos caminhoneiros: sim ou não?". Tem-se o conflito quando uma parte da sociedade veicula uma reivindicação e espera como resposta o "sim", mas uma parte da sociedade - o governo, o judiciário, os empresários etc. - responde com um "não". O "não" de Luhmann (1984, p. 531) é estruturado socialmente, pela sociedade: "Conflitos são, por conseguinte sistemas sociais, e, com efeito, sistemas sociais que oportunamente se constroem em outros sistemas, mas que não assumem o status de sistemas parciais e, ao contrário, existem apenas de modo parasitário".

Conflitos são sistemas-parasita porque tendem a absorver os recursos comunicativos do sistema "hospedeiro", procurando concentrar todos os recursos envolvidos na produção de sentido e influenciar a reprodução das operações comunicativas desse sistema. A força destrutiva do conflito, portanto, não está no 
dissenso; a força destrutiva do conflito está em sua relação com aquele sistema parcial funcionalmente diferenciado em que ele se instala como sistema-parasita, colocando assim em risco a reprodução autopoiética da comunicação no sistema principal. Os exemplos citados acima (o movimento do passe livre de junho de 2013 e a greve dos caminhoneiros de maio de 2018) ilustram o tipo de paralisia social que um conflito pode impor aos sistemas sociais da sociedade.

Pois bem, diante de conflitos, a diferenciação funcional tem de reagir. Conflitos provocam um aumento de complexidade, comunicam expectativas incompativeis entre si. Essa complexidade tem de ser reduzida para a sociedade. Existem dois meios para que o conflito social seja tratado socialmente a fim de evitar efeitos prejudiciais à autopoiese da sociedade: protesto e procedimento. Em síntese, é possível concluir a partir de Luhmann: o conflito é um sistema instável, ele destaca uma contradição, mas não pode se reproduzir como contradição, tem de se converter: (i) em um procedimento jurídico-político, que encerra o conflito com a tomada de uma decisão coletivamente vinculante ou (ii) nos movimentos de protesto, que isolam em si mesmos a negação da sociedade.

\section{Procedimento}

As considerações acerca da relação entre conflito e procedimento nos remetem a um trabalho mais antigo de Luhmann, Legitimação pelo procedimento, livro de 1969 que traz desenvolvimentos notáveis pela articulação entre sua então nascente teoria social, a psicologia social norte-americana e o forte raciocínio jurídico-institucional, merecendo ser retomado à luz da configuração madura da teoria.

Como visto, o conflito é um subsistema social parasitário que consome energia do sistema em que se instala e pode, no limite, pôr em risco sua reprodução autopoiética. 0 procedimento é o antídoto para este mal: $o$ procedimento é a reestruturação comunicativa de expectativas no horizonte de uma decisão que, ao final, deverá ser tomada como vinculante. O procedimento é um sistema de tipo especial porque é oriundo de um conflito; ele é o conflito institucionalmente transformado, é um sistema dentro de um sistema - ao fim e ao cabo, também o procedimento deve ser visto como o fenômeno comunicativo por meio do qual as expectativas dos envolvidos são ajustadas (LUHMANN, 1969).

Há um mal-entendido generalizado acerca da formulação de Luhmann quanto à legitimação pelo procedimento, como se, com isso, pretendesse-se uma extrapolação decisionista e legalista, como se o conceito de procedimento (Verfahren) de Luhmann fosse sinônimo do conceito de processo (Prozess) judicial, legislativo ou administrativo, tal como entendidos pela teoria do direito tradicional; como 
se toda decisão que houvesse seguido um processo determinado pudesse ser considerada legítima. Nada mais equivocado. O procedimento designa sempre e exclusivamente o processo social, comunicativo, de reestruturação de expectativas - e não o processo jurídico-formal de tomada de decisões (não obstante esse procedimento se desenrole com amparo em regramentos jurídico-institucionais). Retomando os exemplos citados, tanto o movimento pelo passe livre quanto a greve dos caminhoneiros reestruturam o antagonismo "sim/não" em um procedimento institucional que culminou em decisões oficiais (a revisão do reajuste das tarifas de ônibus no primeiro caso; medidas de apoio aos caminhoneiros no segundo - frete tabelado, revisão do reajuste do óleo diesel etc.). O procedimento é assim o sistema social que parte do antagonismo “sim/não" estruturado pelo conflito e evolui, no tempo, de forma a reestruturar comunicativamente as expectativas dos envolvidos (e, a rigor, de toda a sociedade), de forma a amoldá-las a uma decisão a ser tomada institucionalmente.

Nesse sentido, ele se diferencia de seu ambiente: (i) materialmente, porque a diferença procedimento/ambiente é interna a uma diferença sistema/ ambiente prévia, de forma que a segunda diferença só existe para desonerar a primeira; (ii) socialmente, na medida em que disponibiliza papéis sociais que condicionam e especializam sobremaneira a interação; e (iii) temporalmente, porque ele tem de chegar a uma decisão e não pode, ao contrário dos sistemas sociais em que está inserido, redundar indefinidamente em uma reprodução autopoiética (o procedimento não se reproduz; ele pode até gerar procedimentos secundários e derivados, mas ele tem de se esgotar em algum momento). Com isso, a diferenciação do procedimento disponibiliza uma vinculatividade de sentido (Sinnverbundenheit) para as ações empíricas, que é disponibilizada para um sistema social principal para a tomada de decisões obrigatórias (LUHMANN, 1969, p. vii-viii). O procedimento tem de ser compreendido como um sistema social muito especializado e transversal - é um sistema auxiliar, um subsistema a serviço de um sistema social principal. Ao mesmo tempo em que não é específico de sistema algum, pode ser disponibilizado para qualquer sistema social parcial cuja rotina de decisão esteja juridicamente disciplinada. "Procedimentos serão vistos como sistemas sociais sincronizados com processos decisórios, mas que não Ihes são idênticos" (LUHMANN, 1969, p. 3).

Sem prejuízo dos sistemas sociais parciais em que a rotina decisória é explicitamente regulada por normas jurídicas (direito e política, bem como seus subsistemas específicos), os procedimentos podem ser empregados por todos os sistemas: na ciência, para tomar a decisão de atribuir determinado título acadêmico ou definir a linha de pesquisa de um instituto ou departamento; na economia, para que uma empresa decida realizar um investimento no mercado 
financeiro internacional ou distribuir dividendos; na educação, para que um aluno seja aprovado ou reprovado. Em todos os sistemas, as decisões são tomadas com base em um procedimento decisório. 0 procedimento é juridicamente regulado desde que se entenda por "regulação jurídica" um regramento em sentido muito lato, que não se confunde com a disciplina legislativa tal como a entendem os juristas (não se trata aqui da produção de leis e decretos) e que não tem uma densidade normativa uniforme em todos os sistemas sociais: as decisões de uma empresa são reguladas por seu estatuto social; uma assembleia de condôminos é regulada pela convenção de condomínio; a divisão de tarefas entre a redação e a equipe editorial de um jornal é regulada por um regimento interno ou um código de conduta específico; uma negociação salarial dispõe de regras próprias pactuadas entre os participantes etc. Em todos esses casos, há um procedimento que, em alguma medida, pode ser considerado juridicamente regulado e que, assim, disponibiliza papéis sociais que podem ser mobilizados para tomar uma decisão. O procedimento é assim a história de uma decisão (LUHMANN, 1969, p. 40).

O caráter vinculante de uma decisão tem de ser socialmente reconhecido, mas esse reconhecimento social não se confunde com a adesão subjetiva ao resultado da decisão propriamente dito. Muito pelo contrário, a legitimação pelo procedimento é responsável pela neutralização social da insatisfação individual, ela explicita os mecanismos sociais pelos quais as expectativas presentes no início de um conflito são reestruturadas comunicativamente e ajustadas à decisão final antes mesmo que ela ocorra, de forma a converter o inconformismo individual em (justa ou, pelo menos, compreensível) resignação. Isso só é possível com recurso aos papéis sociais. Os papéis sociais permitem aos agentes transpor as circunstâncias individuais concretas, pressupondo uma generalização social que respalda a aceitação individual de uma decisão desfavorável. Por essa razão, o comportamento dos participantes no procedimento é decisivo. Esse comportamento não é simplesmente dado ou determinado mecanicamente pelo procedimento, mas estandardizado funcionalmente. A cada momento e para cada papel social estão abertas possibilidades contingentes de participação. A progressão do procedimento no tempo reduz crescentemente a margem de atuação dos envolvidos, forçando a tomada de decisão. Essa decisão somente se impõe aos descontentes se não puder ser revista. A impossibilidade de rever indefinidamente uma decisão exige a construção de legitimidade. A legitimação pelo procedimento é a reestruturação das expectativas daqueles envolvidos no procedimento com vistas a ajustá-las ao resultado final da decisão, ainda desconhecido, antes mesmo que ela ocorra; trata-se, em síntese, do mecanismo social pelo qual os indivíduos aprendem a aceitar decisões de conteúdo ainda desconhecido. Nesse sentido, ela não tem rigorosamente nada a ver com a 
convergência de convicções subjetivas relativas ao acerto da decisão tomada ou com qualquer nível de concordância com seu conteúdo.

A dimensão comunicativa do procedimento está relacionada ao processo de reestruturação de expectativas que, a rigor, nada mais é que um processo de aprendizagem social ("aprendizagem", tal como entendida pelas teorias de atribuição desenvolvidas nas décadas de 1940 a 1960 pela psicologia social norteamericana). Naquele contexto, a psicologia social incorporou fundamentalmente métodos experimentais de análise do comportamento individual, na tentativa de explicá-lo não como decorrência direta da consciência, mas como função dos estímulos sociais externos. O objetivo era explicar os mecanismos sociais subjacentes às manifestações superficiais do comportamento individual observado diretamente. Nesse sentido, o contexto situacional em que o indivíduo se encontra é o fator mais importante para explicar seu comportamento: o valor informacional da ação adjudicada ao agente é tanto maior quanto mais variados sejam os cursos de ação disponíveis para o agente (JONES, 1957, p. 268-269; p. 306).

O procedimento implica a capacidade de aprender a aceitar um resultado contingente em uma situação de incerteza. Essa aprendizagem ocorre como reestruturação de expectativas: as expectativas com as quais os indivíduos se engajam em um procedimento em seu início contam com um grau elevado de insegurança quanto ao conteúdo da decisão final. À medida que o procedimento avança, absorve insegurança alterando as expectativas de forma a ajustá-las à decisão. 0 procedimento não elimina o descontentamento nem o inconformismo com a decisão final, mas procura minimizá-los tanto quanto possível. Por exemplo, em um processo judicial qualquer, dificilmente os agentes envolvidos partem de expectativas idênticas quanto ao resultado final do processo. Considerando o tema da disputa, os argumentos que podem ser suscitados de parte a parte, 0 contexto da disputa e a jurisprudência pertinente, as partes envolvidas na disputa já partem de expectativas diferentes quanto a "ganhar ou perder" a ação. Mas mesmo supondo que as partes tenham expectativas idênticas, o procedimento as vai alterando progressivamente de forma a ajustá-las à decisão final: se uma tutela liminar é concedida a pedido do autor da ação, já é possível supor alguns dos desdobramentos possíveis a partir desse ponto. Eventual parecer do Ministério Público ou laudo técnico, a depender do tipo de demanda judicial, também são elementos que contribuem para que as partes envolvidas "aprendam" o sentido para o qual tende a decisão final (ainda a ser tomada). As partes, portanto, adaptam suas expectativas a este novo estado de coisas, que poderá ser alterado, por exemplo, se um juiz substituto assume o julgamento ou se, no tribunal, algum desembargador pedir vistas do processo e trouxer um argumento totalmente inusitado capaz de reorientar o julgamento. É nesse sentido que os 
agentes aprendem a aceitar a decisão que ainda não conhecem (mas que julgam poder prognosticar em alguma medida).

Esse mecanismo de aprendizagem é explicado pela diferença entre expectativas normativas e expectativas cognitivas (LUHMANN, 1984, p. 436-443; 1980, p. 40-53; 1993, p. 131-143). As expectativas são estruturas dos sistemas. Não é possível abordar aqui, em toda sua extensão, os argumentos de Luhmann para demonstrar porque, na teoria de sistemas sociais, o conceito de estrutura não é em nada equivalente ao funcionalismo estrutural de Parsons (LUHMANN, 1984, p. 377 e ss.). Basta, para nossos presentes fins, lembrar que a teoria de sistemas sociais emprega a diferença estrutura/evento para temporalizar complexidade e que, dessa forma, estrutura e evento se definem e se diferenciam um do outro pelo tipo de relação temporal que permitem que o sistema estabeleça em sua reprodução autopoiética: enquanto os eventos permitem construir os elementos dos sistemas como elementos de ação (eventos codificados são informações, eventos não codificados são ruídos, irritação) que, como tais, demarcam temporalmente uma ocorrência, uma diferença antes/depois, as estruturas representam limitações de margem de escolha para que os eventos ocorram (LUHMANN, 1984, p. 77; 398-399). Nesse sentido, as expectativas não devem ser entendidas subjetivamente como estados de espírito interiores, mas como uma redução objetivamente determinada das possibilidades de escolha disponíveis, tanto para sistemas psíquicos quanto para sistemas sociais (LUHMANN, 1984, p. 397).

Mas nem toda expectativa é reestruturada pelo procedimento. Enquanto as expectativas cognitivas permitem adaptação à realidade (porque se alteram e se reestruturam de acordo com as frustrações experimentadas), as expectativas normativas sobrevivem à frustração, são estruturas contrafáticas (não são revistas diante de um desapontamento). O importante não é investigar o conteúdo de uma expectativa satisfeita ou frustrada, mas observar o que acontece diante da frustração, observar se as expectativas são mantidas, alteradas ou abandonadas. Apenas as expectativas cognitivas permitem aprendizado. A reestruturação permanente de expectativas cognitivas tem como fundamento preservar as expectativas normativas. Por isso, é preciso que o procedimento produza a aceitação da decisão:

Legitimação pelo procedimento não é algo tal como a justificação [de uma decisão] pelo direito processual, embora os procedimentos pressuponham um regramento jurídico; trata-se, ao contrário, da reestruturação de expectativas por meio do processo comunicativo fático que transcorre de acordo com regramentos jurídicos, portanto, de um acontecimento efetivo e não de uma relação de sentido normativa. (LUHMANN, 1969, p. 37) (Grifos no original) 
A passagem é elucidativa. A legitimação é obtida pela reestruturação permanente de expectativas perpetrada pela comunicação que se satura ao longo do procedimento juridicamente regulado até culminar em uma decisão. A aprovação de uma emenda constitucional que responda a um conflito social (necessária, por exemplo, para criação de um programa de transferência de renda, para desoneração fiscal de setores produtivos ou para a permissão ou a proibição do aborto) é um procedimento juridicamente regulado que ilustra a função do procedimento no sistema político: há regras de competência para propositura de projetos de emenda constitucional, prazos para apresentação de emendas, divisão de trabalho entre comissões temáticas, um número mínimo de sessões de discussão que, via de regra, não pode ser suprimido; tudo isso antes que a proposta chegue ao plenário do parlamento para votação final - essa, a única decisão obrigatória, também ela sujeita a regras de quórum mínimo, intervalo ou turnos de trabalho e expedientes específicos de votação e contabilização de votos. 0 transcurso do procedimento se encarrega de reestruturar as expectativas dos envolvidos (governo e oposição, opinião pública e todos os indivíduos que podem vir a ser afetados pela decisão a ser tomada), de forma a ajustá-las à decisão final antes mesmo que ela tenha efetivamente ocorrido: se o clima do debate se configura de maneira favorável à oposição, o governo ajusta suas expectativas diante da derrota iminente e chega à decisão final condicionado a aceitá-la. Essa reestruturação de expectativas é saturada temporalmente e, à medida que o procedimento avança, há cada vez menos margem de manobra para os participantes.

Essa dinâmica tem outra consequência, igualmente importante, algo que poderíamos chamar de um "efeito dialético": o procedimento suaviza e aprofunda, ao mesmo tempo, o conflito social: suaviza-o, na medida em que o conflito se restringe ao desempenho de papéis sociais; aprofunda-o, na medida em que todo o desempenho de um papel social está engajado no conflito. O conflito é aprofundado na tomada de uma decisão que, socialmente considerada, mantémse adstrita a limites muito específicos. Os papéis sociais permitem desativar os conflitos sociais concretos e reestruturá-los em um nível abstrato, descolado das personalidades individuais: ao mesmo tempo em que se trata apenas do desempenho de papéis (o que diminui a importância do conflito), a gravidade do conflito é elevada ao máximo (nos limites estritos do procedimento) - o que permite que o conflito seja mantido e conservado como sistema. Com isso, a função do procedimento não é produzir consenso ou evitar desilusões. Ao contrário:

Sua função não repousa no impedimento de decepções, mas sim em trazer decepções inevitáveis à forma final de um ressentimento privado difusamente difundido, que não pode se transformar em instituição. [...] A função do procedimento é conseqüentemente a 
especificação do descontentamento e a fragmentação e absorção de protestos. 0 motor do procedimento é a incerteza quanto a seu desfecho. Essa incerteza é a força propulsora do procedimento, seu fator verdadeiramente legitimador. [...] A incerteza se torna o motivo a exigir que os destinatários da decisão sejam levados a um trabalho cerimonial não-remunerado. [...] Então uma rebelião contra a decisão quase não tem sentido e, em todo caso, já não tem mais qualquer chance. [...]. A decisão é aceita como vinculante sem que isso dependa de uma disposição interior [...]. Legitimação pelo procedimento, por conseguinte, não conduz necessariamente ao consenso real, à comunhão harmônica de pontos de vista sobre o justo e o injusto. [...] De maneira muito geral, não se há de compreender a função social de um mecanismo de solução de conflitos como o desencadeamento de determinados processos psíquicos de aceitação, mas antes como imunização do sistema social contra esses processos. [...] Parece, por isso, que a legitimação pelo procedimento não consiste em vincular internamente o afetado [pela decisão], mas sim em isolá-lo como fonte de problemas e pôr a ordem social independentemente de seu acordo ou de sua rejeição (LUHMANN, 1969, p. 116-117; 119-120)

Não obstante toda essa argumentação, Luhmann (1969, p. 199) chega a afirmar curiosamente que os procedimentos não bastam "por si só" para provocar e explicar a contínua reestruturação das expectativas ou a aceitação das decisões. $O$ autor lança uma dúvida sobre seus próprios desenvolvimentos e a deixa em aberto, sem indicar que tipo de resposta seria possível. 0 ponto, se não é resolvido pelo próprio Luhmann, não afeta a sequência de nosso argumento.

Se o quanto dito nesta seção procede, não há então alternativas ao procedimento? É dizer, a sociedade é capaz de tornar todo conflito em um procedimento? A sociedade funcionalmente diferenciada não é capaz dessa tarefa - e, a rigor, ela sequer sente necessidade de converter todo conflito em procedimento. Ela conta com outra estrutura funcional capaz de absorver a complexidade da rejeição de expectativas comunicativas. Nem toda insatisfação pode ou deve ser absorvida pelo procedimento. Quando isso não ocorre, entram em cena os novos movimentos sociais, designados por Luhmann sugestivamente como movimentos de protesto.

\section{Protesto}

Os movimentos de protesto completam esse quadro. O ponto central acerca de tais movimentos não está relacionado ao tratamento tradicionalmente 
dispensado ao problema do collective behavior da psicologia social de Chicago ou ao problema da ação coletiva posto pelo individualismo metodológico e problematizado no quadro da rational choice theory, a questão não é apreender os movimentos sociais pela diferença individual/coletivo. Se os sistemas sociais constroem pessoas, eles podem também construir atores coletivos conforme classes, grupos, camadas sociais e quaisquer outros critérios que atendam às suas necessidades (como, e.g., a comunidade acadêmica, a opinião pública, os colegiados encarregados de tomar decisões - o tribunal, o conselho o júri - o mercado, os trabalhadores, o governo, a oposição, o público). Não se trata da agregação de unidades individuais em um coletivo, mas da emergência tanto do individual quanto do coletivo, produzida de acordo com processos de imputação de cursos de ação responsáveis pela produção de sentido (WILLKE, 1978, p. 385; AHLEMEYER, 1989, p. 187).

O ponto central da questão está no fato de que os movimentos sociais tentam mobilizar a sociedade contra ela mesma, a partir de dentro dela mesma, mas como se estivessem fora ou acima da sociedade:

Com a forma do protesto torna-se visível que os participantes procuram de fato influência política, mas não pelo caminho normal. [...] A comunicação do protesto se dá, com efeito, na sociedade, pois do contrário ela não seria comunicação, mas de tal modo, como se estivesse de fora. (LUHMANN, 1997, p. 852-853) (Grifos no original) ${ }^{1}$

O paradoxal dos movimentos de protesto está no fato de que a tentativa de contradizer a sociedade funcionalmente diferenciada redunda, por conta das estruturas sociais disponibilizadas pela evolução da própria diferenciação funcional da sociedade moderna, na afirmação dessa sociedade. Aqui se revela outro "efeito dialético" da diferenciação funcional da sociedade: se, pelo procedimento, os conflitos sociais são postos como conflitos negados porque permitidos, institucionalizados; os movimentos de protesto, em complemento, fazem com que a reação da sociedade às suas contradições internas reforce as estruturas contraditórias da própria sociedade. Vejamos em maior detalhe como essa inversão se concretiza socialmente.

Os chamados novos movimentos sociais não se coadunam com o clássico modelo socialista das lutas de classe por, pelo menos, três razões constitutivas: (i) não se originam das posições de classe de acordo com a posição ocupada na divisão social do trabalho e na organização da fábrica; (ii) não têm mais uma única

Cf. igualmente Luhmann (1986, p. 236) e Luhmann e Hellmann (1996). 
meta (a revolução, o socialismo ou, conceda-se, uma melhor distribuição de renda), capaz de orientar teleologicamente a luta política e social; (iii) os temas trazidos para a disputa política são múltiplos, heterogêneos e, não raro, incongruentes. Há aqui um ponto interessante a ser destacado: os novos movimentos sociais são radicalmente individualistas. Se o movimento proletário permitia distinguir a classe "em-si" da classe "para-si", para utilizarmos o jargão marxiano; i.e., se a partir das posições de classe era possível apontar na direção da luta política consciente (por mais que remanescesse o problema da consciência de classe), os novos movimentos sociais se enraízam não na solidariedade coletiva e engajada, mas fora dessa esfera social - no interior do próprio indivíduo. Não há uma comunidade de condições de vida subjacente ao movimento social capaz de fundamentar o engajamento coletivo: esse engajamento coletivo é construído antes com base em problemas rigorosamente individuais de busca de sentido (Sinnsuche) e de autorrealização (Selbstverwirklichung) pessoal que, como tais, alcançam apenas um enfeixamento precário na focalização como movimento social (LUHMANN, 1997, p. 851).

O argumento de Luhmann é que os novos movimentos sociais não podem ser considerados rigorosamente sociais porque não estão plenamente constituídos na esfera objetiva de generalização simbólica e de produção de sentido, mas que sua manifestação, nessa esfera, tem recorrentemente de ser recuperada e imputada à esfera da consciência individual. Isso não é por si só o problema. O problema é que a comunicação, quando não está completamente autonomizada ante a consciência, tem capacidade operativa diminuta e pouco alcance na orientação do comportamento. Os novos movimentos sociais preparam motivos, compromissos e vinculações a temas críticos, mas essa vinculação não é mediada por uma generalização simbólica objetivamente institucionalizada pela sociedade - se os movimentos de protesto não se deixam reduzir a interações simples, não são, contudo, capazes de estruturar organizações propriamente ditas.

Isso deixa claro também, por outro lado, que a diferenciação funcional da sociedade não significa, como querem alguns críticos, o fim do indivíduo ou "uma sociedade sem homens" (IZUZQUIZA, 1990); ao contrário, os novos movimentos sociais são consequência de uma sociedade cada vez mais individualista, de uma sociedade apoiada em um individualismo muito mais profundo do que o utilitarismo liberal-burguês de John Stuart Mill; são o produto de uma individualização radicalizada.

Os movimentos de protesto são sistemas sociais de tipo muito específico. Não são sistemas sociais imediatamente autopoiéticos. O protesto introduz uma diferença centro/periferia, mas se localiza na periferia. A periferia protesta contra o centro do sistema, exigindo dele que a leve a sério. Como não há mais um único 
centro na sociedade funcionalmente diferenciada, mas apenas centros construídos por sistemas funcionais parciais, os movimentos de protesto somente podem se situar dentro desses sistemas funcionais parciais, ainda que na periferia (LUHMANN, 1997, p. 853). Nesse sentido, os movimentos sociais se concentram na periferia do sistema político, notadamente. Os sistemas de protesto somente deixam a forma precariamente estabelecida pela diferença periferia/centro, i.e., somente podem ser considerados sistemas autopoiéticos quando mobilizam recursos (financeiros, publicitários, jurídicos, jornalísticos etc.) para determinado fim que permite a reprodução do protesto.

A diferença periferia/centro é introduzida como forma de organizar uma identidade coletiva em torno de um tema de protesto, ainda que essa identidade seja apenas frouxamente coletiva; mas quando essa diferença é replicada internamente pela constituição de um centro na periferia, que organiza o engajamento dos participantes, capta recursos para financiar as atividades de protesto e procura lhes assegurar perenidade e visibilidade, é possivel passar do movimento de protesto espontâneo, ad hoc, a um sistema operativamente fechado. Os movimentos sociais dependem de um núcleo duro de direção e estratégia que coordena e mobiliza a militância (LUHMANN, 1997, p. 864).

Do ponto de vista técnico da construção da teoria, o movimento de protesto é uma forma invertida: introduz uma diferença periferia/centro para se situar na periferia da sociedade, mas, uma vez estabilizada essa diferença, sua replicação interna ocorre pela diferença centro/periferia, de forma a constituir um centro no próprio movimento social. Com isso, os movimentos de protesto negam efetivamente a sociedade, mas o fazem copiando-a em si mesmos. Eles criticam a sociedade em que se inserem, mas se organizam tendo essa sociedade como modelo: não participam da política parlamentar, mas organizam eleições internas ao movimento para eleger seus dirigentes; reivindicam a democratização de esferas institucionais mais amplas, mas têm mecanismos internos de centralização decisória; criticam a aproximação entre o dinheiro e o poder, mas desenvolvem seus próprios canais de financiamento e assim por diante (LUHMANN, 1997, p. 864). Os novos movimentos sociais criticam a sociedade em que se inserem como se estivessem fora dela, mas, nesse movimento, internalizam as próprias estruturas sociais que pretendem superar.

A forma protesto, como forma de dois lados que indica seu lado interno (movimento de protesto/adversários), desempenha função equivalente à função que os códigos binários executam nos sistemas funcionais - sem, contudo, o recurso à diferenciação de um meio de comunicação simbolicamente generalizado. Note-se, com isso, que o próprio protesto tem de segmentar a sociedade em dois lados e, com isso, já bloqueia estruturalmente a possibilidade de uma 
responsabilidade imputável à sociedade como um todo (porque o movimento de protesto teria também de ser responsável pela sociedade tal como ela se encontra - o que é excluído como condição de existência do protesto) (LUHMANN, 1997, p. 855).

Essa situação é pressuposto dos movimentos de protesto: do contrário, eles seriam envolvidos na solução a ser encontrada para determinado problema e, nesse sentido, restariam "procedimentalizados", por assim dizer. É claro que essa alternativa pode ser mobilizada estrategicamente: por exemplo, se militantes ecológicos tomam de assalto uma madeireira e negociam a desocupação, o movimento estaria aparentemente participando da solução de um problema. Mas esse problema (a invasão) é criado pelo movimento com a única função de destacar um outro problema da sociedade (o desmatamento). Ao negociar a desocupação, o movimento social participa da solução do problema que ele mesmo criou, mas não da solução do problema da sociedade. Essa alternativa é adotada sempre para ressaltar o tema do protesto: os militantes não desocupam a madeireira se sentido responsáveis por monitorar a preservação ambiental - a tarefa continua a cargo das agências oficiais de proteção ambiental.

O movimento de protesto chama a atenção, alarma a sociedade e cobra explicações, providências e sanções - desde que não tenha de fazer mais nada a respeito. Dessa forma, os movimentos de protesto se diferenciam da oposição partidária: esta última faz parte do sistema político e se caracteriza não por ser contra o governo, mas pela prontidão e aptidão imediatas em assumir o governo ou, pelo menos, em influenciar e codeterminar os rumos do governo. Pela mesma razão, a greve de operários fabris não é um movimento de protesto: porque a negociação e a construção conjunta de uma solução são praticamente intrínsecas à greve - os grevistas são também responsáveis pelo problema a ser solucionado tanto quanto pela solução encontrada.

Há aqui, claro, um viés na análise de Luhmann. Quando os movimentos de protesto são formulados como reivindicação de direitos, eles não têm a forma de um antagonismo radical, mas veiculam uma afirmação incremental de direitos (MCCANN, 1994; FRIEDMAN; LANDINSKY, 2001; SCHEINGOLD, 2004). Luhmann afirmaria que, nesses casos, os movimentos sociais não configurariam protesto, mas procedimento, no sentido de reestruturar expectativas da sociedade. Não obstante, há de fato um ponto em que a radicalidade do protesto converge com a demanda por direitos. Esse é o momento em que os critérios de inclusão e exclusão (em termos de direitos) são discutidos politicamente. Essa discussão, que extrapola a presente investigação, foi abordada em outra oportunidade (BACHUR, 2020). 
Os movimentos de protesto têm de desconsiderar aquele contra o qual se protesta: não é importante compreender o outro lado; muito pelo contrário, os pontos de vista do outro lado, dos adversários do movimento de protesto, são levados em consideração apenas como momentos táticos de suas próprias operações. Isso explica porque - por mais restrita que seja a pauta temática de um movimento de protesto qualquer, por menor que seja sua militância engajada o protesto tem de ser inexoravelmente radical em suas reivindicações. Sua pauta temática só não pode ser inexpressiva: tem de veicular reivindicações socialmente dignas de nota e das quais não se pode abrir mão. Por essa razão, os movimentos de protesto não podem transigir com seus adversários e, por essa mesma razão, quando se deparam com a possibilidade de tomar parte em um procedimento (que, como visto, significa cooperar por meio do conflito permitido), têm de se autoexilar na sociedade, têm de se converter em uma espécie de autismo deliberado. Por exemplo: se um parlamento qualquer está prestes a votar uma lei permitindo o aborto, não seria de se estranhar que o movimento contrário à referida lei preferisse radicalizar sua reivindicação, mantendo uma intransigência que pode ser ignorada por governo e oposição na votação da lei, ao invés de negociar restrições às hipóteses de permissão do aborto; porque, afinal de contas, isso significaria tomar parte no procedimento decisório e, nesse sentido, colaborar com a aprovação de uma lei contra a qual se protesta veementemente. Se o movimento negociasse cláusulas para a realização do aborto, poderia reduzir as hipóteses legalmente permitidas - ao custo de uma flexibilização do protesto, claro. Mas não, o fechamento operacional do sistema de protesto exige a radicalização do movimento social, mesmo se o resultado final for a eventual permissão generalizada do aborto. ${ }^{2}$

Tudo isso reforça o paradoxo dos movimentos de protesto: só se está satisfeito quando se está insatisfeito - o que sugere que o verdadeiro desiderato do protesto talvez seja a preservação (razoavelmente inócua) da insatisfação. É claro que a ampliação de direitos parte muitas vezes de movimentos de protesto - que, com efeito, precisam participar dos procedimentos decisórios para fazer valer suas reivindicações. 0 protesto que mantém sua distância ante o procedimento apenas insula a insatisfação do restante da sociedade, neutralizando-a. Em função disso, os movimentos de protesto não se prestam a oferecer uma reflexão de segundo grau, uma reflexão da reflexão para o subsistema funcional no qual se inserem, i.e., não são rigorosamente considerados como um "outro lado" para além do

2 Note-se que não fazemos, aqui, qualquer juízo de valor quanto ao tema; trata-se apenas de um exemplo hipotético que ajuda a entender como funciona socialmente a lógica da comunicação de protesto. O exemplo poderia ser pensado não apenas no caso oposto, como também em relação a temas igualmente sujeitos a posicionamentos radicais, tais como a pena de morte ou a eutanásia. 
qual o sistema funcional poderia refletir sobre si mesmo; permanecem, apenas mas é justamente isso que assegura o caráter específico dos movimentos de protesto - como revolta, insatisfação.

Essa configuração encurrala o protesto em um beco sem saída: ao mesmo tempo em que sua agenda é radicalmente irrenunciável porque extremamente relevante, não há espaço para a transigência - por conseguinte, tanto o sucesso quanto o fracasso do protesto são fatais para o movimento (LUHMANN, 1997, p. 858). O sucesso é fatal porque se o tema é incorporado às operações do sistema político ou econômico, por exemplo, caberá ao movimento apenas o reconhecimento histórico de ter provocado uma alteração no sistema. O fracasso é fatal porque desmobiliza o movimento. É só pensarmos, mais uma vez, no caso do movimento pelo passe livre estudantil no município de São Paulo: inicialmente disparado por conta do reajuste da passagem de ônibus de $R \$ 4,00$ para $R \$ 4,20$ em junho de 2013, o movimento conseguiu uma vitória de curto prazo, fazendo as autoridades governamentais recuarem do reajuste - mas, ao mesmo tempo, quando conseguiu o que queria, o movimento se esvaiu; por outro lado, no médio prazo, o movimento não foi capaz de reativar a mobilização social em janeiro de 2019 , quando a tarifa subiu de $\mathrm{R} \$ 4,00$ para $\mathrm{R} \$ 4,30$.

Não é de se esperar, portanto, que os movimentos de protesto compreendam porque o mundo é como é, nem que eles consigam esclarecer o que aconteceria se a sociedade cedesse a seus argumentos e pretensões (LUHMANN, 1997, p. 857). Os movimentos de protesto não são capazes de oferecer uma alternativa à sociedade - e tal não se deve deles esperar. "Falta teoria aos novos movimentos sociais" (LUHMANN, 1986, p. 234).

$\mathrm{E}$, não obstante todo o radicalismo dos movimentos de protesto, a veemência com que se insurgem contra o "capitalismo" ou "o sistema", o ponto cego que Ihes permite negar a sociedade é precisamente este: os próprios movimentos de protesto são subsistemas sociais produzidos pela própria diferenciação funcional da sociedade, em especial de seu sistema político. "Caso se pretenda, ainda, atribuir uma função também para os movimentos de protesto, seria possível dizer: trata-se de converter em operações a negação da sociedade dentro da sociedade" (LUHMANN, 1997, p. 864).

Com isso, podemos destacar o último "efeito dialético" da diferenciação funcional da sociedade que pretendemos abordar neste artigo: se os movimentos de protesto mobilizam a sociedade funcionalmente diferenciada contra ela mesma, a própria sociedade, por sua vez, e por intermédio de seu sistema político, mobiliza-se de forma a reagir ao protesto: tomando-o a sério (o que elimina a razão do protesto) ou ignorando-o (o que mantém o protesto isolado 
na sociedade). Em qualquer dos casos, os novos movimentos sociais não são capazes de oferecer uma alternativa para transcender os limites da sociedade funcionalmente diferenciada.

\section{Conclusão}

A sociedade funcionalmente diferenciada se caracteriza por uma ambivalência fundamental no que diz respeito ao conflito como categoria política e social: a sociedade dos sistemas autopoiéticos tem mais e menos conflito ao mesmo tempo. A generalização do conflito suaviza sua gravidade, sua importância na dinâmica evolutiva da sociedade. A contradição social, entendida em regra como um fator de mudança social, apresenta-se na sociedade funcionalmente diferenciada como um fator de conservação social. Daí a ambivalência do conflito na sociedade funcionalmente diferenciada: os sistemas sociais permitem mais conflitos que, por essa razão, representam menos risco de um conflito social generalizado (aquilo que os marxistas chamavam de "revolução").

No caso dos procedimentos decisórios, o conflito força uma decisão pelas instituições jurídico-políticas; no caso dos movimentos de protesto, a revolta social fica ilhada em um reduto de protesto que almeja influência política e não pode tomar parte nas decisões da sociedade. Nos dois casos, a diferenciação funcional da sociedade esteriliza a revolta e funcionaliza o protesto - dessa maneira, a autopoiese da sociedade não é comprometida.

A questão que este artigo permite então levantar, mas que no momento tem de ser deixada em aberto, diz respeito à capacidade da democracia parlamentar em se apropriar da energia comunicativa desencadeada pelos movimentos de protesto de forma a revigorar seus procedimentos decisórios oficiais. Uma possível resposta - marcadamente kantiana - a essa questão pode ser encontrada na obra madura de Habermas, notadamente em sua teoria do direito e da democracia deliberativa.

Uma alternativa menos idealista e mais próxima da dinâmica institucional concreta da política contemporânea poderia propor uma teoria da democracia a partir de uma leitura não ortodoxa da teoria de sistemas de Luhmann, focada na energia produtiva do dissenso e na sua capacidade de veicular demandas por inclusão: os movimentos de protesto poderiam ser vistos como desencadeadores de demandas por inclusão em termos de acesso a direitos, de forma que o sistema político seja chamado a redefinir, para os outros sistemas da sociedade, critérios de inclusão e exclusão. Não obstante o diagnóstico atual da democracia liberal tenda a acentuar suas crises e sua incapacidade decisória, este ainda parece 
ser o único caminho para permitir que lutas políticas coletivas se convertam na ampliação e na afirmação de direitos.

\title{
Conflict, protest and procedure in Niklas Luhmann's systems theory
}

\begin{abstract}
Contemporary society, described by Niklas Luhmann's social systems theory as a functionally differentiated society, stabilizes itself through contradictions. Reversing the classic intuition of social theory, contradiction becomes a component for preserving social structures, and it would be no exaggeration to recognize that society reveals itself as much integrated as increases its capability of dealing with contradictions. The purpose of this paper is to develop this point of view having as guideline the conceptual articulation of conflicts, procedure and the so called protest movements, the usual ways for reclaiming the affirmation of individual and social rights, within the framework of Luhmann's social systems theory.
\end{abstract}

Keywords: Niklas Luhmann. Social systems theory. Social conflict. Protest movements.

Contents: $\mathbf{1}$ Introduction: social conflict, contradiction and social dynamics - $\mathbf{2}$ Conflict as a social system - $\mathbf{3}$ Procedures - $\mathbf{4}$ Protest movements - $\mathbf{5}$ Concluding Remarks - References

\section{Referências}

AHLEMEYER, Heinrich W. Was ist eine soziale Bewegung? Zeitschrift für Soziologie, ano 18, n. 3, p. 175-191, 1989.

BACHUR, João Paulo. A performatividade da exclusão e as lutas por inclusão: questões distributivas a partir da teoria de sistemas sociais. Sociologia \& Antropologia, v. 10, n. 1, p. 129-154, 2020.

BACHUR, João Paulo. A diferenciação funcional da religião na teoria social de Niklas Luhmann. Revista Brasileira de Ciências Sociais, v. 26, n. 76, p. 177-190, 2011.

BERGHAUS, Margot. Luhmann leicht gemacht: eine Einführung in die Systemtheorie. Köln: Böhlau, 2003.

BERGMANN, Werner Was bewegt die soziale Bewegung? Überlegungen zur Selbstkonstitution der "neuen" sozialen Bewegungen. In: BAECKER, Dirk et alii (Org.). Theorie als Passion. Niklas Luhmann zum 60. Geburtstag, Frankfurt: Suhrkamp, 1987.

BONACKER, Thorsten. Kommunikation zwischen Konsens und Konflikt. Möglichkeiten und Grenzen gesellschaftlicher Rationalität bei Jürgen Habermas und Niklas Luhmann. Oldenburg: BIS/Uni-OIdenburg, 1997.

BRUNKHORST, Hauke. Kommentar. In: MARX, Karl. Der achzehnte Brumaire des Louis Bonaparte. Frankfurt am Main: Suhrkamp, 2007.

COHEN, Jean L. Strategy or identity: new theoretical paradigms and contemporary social movements. Social Research, v. 52, n. 4, p. 663-716, 1985.

CORSI, Giancarlo; ESPÓSITO, Elena; BARALDI, Claudio. Glosario sobre la Teoría Social de Niklas Luhmann. Tradução de M. R. Pérez e C. Villalobos. Barcelona: Anthropos, 1996. 
DAHRENDORF, Ralf. Soziale Klassen und Klassenkonflikt in der industriellen Gesellschaft. Stuttgart: Enke, 1957.

DOMINGUES, José Maurício; BRINGEL, Bernardo. Teoria crítica e contestações sociais. In: BRINGEL, Breno; GOHN, Maria da Gloria (Org.). Para além do novo: o estudo dos movimentos sociais na era global. Petropolis: Vozes, 2012.

EDER, Klaus. The 'new social movements': moral crusades, political pressure groups, or social movements? Social Research, v. 52, n. 4, p. 869-890, 1985.

FRIEDMAN, Lawrence; LANDINSKY, Jack, O direito como instrumento de mudança social incremental. In: SOUTO, Cláudio; FALCÃO, Joaquim. Sociologia e direito: textos básicos para a disciplina de sociologia jurídica. 2. ed. São Paulo: Pioneira, 2001.

GOHN, Maria da Glória, Teoria dos movimentos sociais: paradigmas clássicos e contemporâneos. São Paulo: Loyola, 1997.

HALFMANN, Jost. Soziale Bewegungen und Staat. Nicht-intendierte Folgen neokorporatistischer Politik. Soziale Welt, v. 3, p. 294-312, 1984.

HEGEL, Georg Wilhelm Friedrich. Grundlinien der Philosophie des Rechts oder Naturrecht und Staatswissenschaft im Grundrisse. Werke 7. 4. ed. Frankfurt am Main: [s.n.], 1995.

HIRSCHMAN, Albert O. Social conflicts as pillars of democratic market society. Political Theory, v. 22, n. 2, p. 203-218, 1994.

HONNEHT, Axel. Kampf um Anerkennung: Zur moralischen Grammatik sozialer Konflikte. Frankfurt am Main: Suhrkamp, 1992.

HOSTER, Detlef. Niklas Luhmann. München: Beck, 1997.

IZUZQUIZA, Ignacio. Sodiedade sin hombres: Niklas Luhmann o la teoría como escándalo. Barcelona: Anthropos, 1990.

JONES, Edward. Foundations of social psychology. New York: Willy, 1957.

KNEER, Georg; NASSEHI, Armin. Niklas Luhmanns Theorie sozialer Systeme: eine Einführung. 2. ed. München: Wilhelm Fink, 1994.

KOUVELAKIS, Stathis. Philosophy and Revolution: from Kant to Marx. Tradução de G. M. Goshgarian, London \& New York: Verso, 2003.

KRAUSE, Detlef. Luhmann-Lexikon: eine Einführung in das Gesamtwerk von Niklas Luhmann. Stuttgart: Ferdinand Enke, 1999.

LUHMANN, Niklas (1969). Legitimation durch Verfahren. Frankfurt am Main: Suhrkamp, 1983.

LUHMANN, Niklas (1980). Rechtssoziologie. 3. ed. Opladen: Westdeutscher, 1987.

LUHMANN, Niklas (1986). Ökologische Kommunikation. Kann die moderne Gesellschaft sich auf ökologische Gefährdungen einstellen? 4. ed. Wiesbaden: VS, 2004.

LUHMANN, Niklas (1987). Was ist Kommunikation?. In: LUHMANN, Niklas. Soziologische Aufklärung 6. Wiesbaden: VS Verlag für Sozialwissenschaften, 2005.

LUHMANN, Niklas. Das Recht der Gesellschaft. Frankfurt am Main: Suhrkamp, 1993.

LUHMANN, Niklas. Die Funktion der Religion. Frankfurt am Main: Suhrkamp, 1977. 
LUHMANN, Niklas. Die Gesellschaft der Gesellschaft. Frankfurt am Main: Suhrkamp, 1997.

LUHMANN, Niklas. Die Politik der Gesellschaft. Frankfurt am Main: Suhrkamp, 2000.

LUHMANN, Niklas. Einführung in die Systemtheorie. Org. Dirk Baecker. 2. ed. Heidelberg: Carl-AuerSystem. 2004.

LUHMANN, Niklas. Einführung in die Theorie der Gesellschaft. Org. Dirk Baecker. Heidelberg: Carl-AuerSystem, 2005.

LUHMANN, Niklas. Introducción a la Teoría de Sistemas. Org. Javier Torres Nafarrate. Barcelona: Anthropos, 1996.

LUHMANN, Niklas. Soziale Systeme: Grundriß einer allgemeinen Theorie. Frankfurt am Main: Suhrkamp, 1984.

LUHMANN, Niklas; HELLMANN, Kai-Uwe (Org.). Protest. Frankfurt am Main: Suhrkamp, 1996.

MARX, Karl (1852). Der achtzehnte Brumaire des Louis Bonaparte. In: MARX, Karl; ENGELS, Friedrich. Werke. Berlin: Dietz, 1983. t. 8.

MARX, Karl; ENGELS, Friedrich (1848). Manifest der Kommunistischen Partei. In: MARX, Karl; ENGELS, Friedrich. Werke. Berlin: Dietz, 1983. t. 4.

MCCANN, Michael. Rights at work: pay equitiy reform and the politics of legal mobilization. Chicago: University of Chicago Press, 1994.

NOBRE, Marcos. Choque de democracia: razões da revolta. São Paulo: Companhia das Letras, 2013. E-book.

OFFE, Claus (1986). Strukturprobleme des kapitalistischen Staates. Frankfurt/New York: Campus, 2006.

REESE-SCHÄFER, Walter. Luhmann zur Einführung. Hamburg: Junius, 1992.

SCHEINGOLD, Stuart A. The politics of rights: lawyers, public policy and political change. Michigan: University of Michigan Press, 2004.

SCHIMANK, Uwe. Theorien gesellschaftlicher Differenzierung. 3. ed. Wiesbaden: VS, 2007.

SPENCER-BROWN, George. Laws of form. New York: Bantam, 1973.

TILLY, Charles. Models and realities of popular collective action. Social Research, v. 52, n. 4, p. 717$747,1985$.

TOURAINE, Alain. An introduction to the study of social movements. Social Research, v. 52, n. 4, p. $749-787,1985$.

WEBER, Max (1920). Zwischenbetrachtung: Theorie der Stufen und Richtungen religiöser Weltablehnung. In: WEBER, Max. Gesammelte Aufsätzse zur Religionssoziologie. 9. ed. Tübingen: J. C. Mohr (Paul Siebeck), 1988. v. I.

WEBER, Max. 1904/1905. 2. ed. 1920, Bodenheim: Athenäum, 1993.

WILLKE, Helmut. Systemtheorie und Handlungstheorie - Bemerkungen zum Verhältnis von Aggregation und Emergenz. Zeitschrift für Soziologie, ano 7, n. 4, p. 380-389, 1978. 
Informação bibliográfica deste texto, conforme a NBR 6023:2018 da Associação Brasileira de Normas Técnicas (ABNT):

BACHUR, João Paulo. Conflito, protesto e procedimento na teoria de sistemas de Niklas Luhmann. Direitos Fundamentais \& Justiça, Belo Horizonte, ano 14, n. 42, p. 507-534, jan./jun. 2020.

Recebido em: 18.04.2019

Pareceres: 26.04.2019, 12.09.2019, 09.03.2020

Aprovado em: 13.03.2020 